Association for Information Systems AIS Electronic Library (AISeL)

Wirtschaftsinformatik Proceedings 2001

Wirtschaftsinformatik

September 2001

\title{
Ownership Structures of Electronic B2B Marketplaces - A Multi-perspective Analysis
}

Stefan Baldi

European Business School, Schloss Reichartshausen, Stefan.Baldi@ebs.de

Hans P. Borgmann

European Business School, Schloss Reichartshausen, hans.borgmann@ebs.de

Follow this and additional works at: http://aisel.aisnet.org/wi2001

\section{Recommended Citation}

Baldi, Stefan and Borgmann, Hans P., "Ownership Structures of Electronic B2B Marketplaces - A Multi-perspective Analysis" (2001). Wirtschaftsinformatik Proceedings 2001. 43.

http://aisel.aisnet.org/wi2001/43

This material is brought to you by the Wirtschaftsinformatik at AIS Electronic Library (AISeL). It has been accepted for inclusion in Wirtschaftsinformatik Proceedings 2001 by an authorized administrator of AIS Electronic Library (AISeL). For more information, please contact elibrary@aisnet.org. 
In: Buhl, Hans Ulrich, u.a. (Hg.) 2001. Information Age Economy; 5. Internationale Tagung Wirtschaftsinformatik 2001. Heidelberg: Physica-Verlag

ISBN: 3-7908-1427-X

(C) Physica-Verlag Heidelberg 2001 


\title{
Ownership Structures of Electronic B2B Marketplaces - A Multi-perspective Analysis
}

\author{
Stefan Baldi, Hans P. Borgmann \\ European Business School, Schloss Reichartshausen
}

\begin{abstract}
In this paper we develop a framework for the ownership structures of electronic markets and contrast different alternatives by using a case study in the automotive industry. Focus is General Motors' decision to join the industry electronic market place Covisint and Volkswagen's decision to build an individual solution. Building on multiple theories from inter-organizational relationship formation we analyze the advantages and disadvantages of private exchanges vs. consortium-based exchanges vs. third party exchanges and illustrate these within our case, working towards a comprehensive contingency framework.
\end{abstract}

Keywords: Electronic Markets, B2B, Ownership Structure, Automotive Industry, Consortia

\section{Introduction}

The emergence of consortium-based electronic markets has recently gained considerable attention. In 2000 a total of 66 newly founded consortia in 18 different industries have been counted [WaCh00]. Two of the most prominent examples are Covisint - founded by General Motors, Ford, and DaimlerChrysler - in the automotive industry and Transora in the consumer goods industry, backed by more than 50 leading companies including Nestlé, Kellogg, and Coca-Cola.

While research has paid considerable attention to electronic markets in general (e.g. [Bako98, GrRa99]) it does not explicitly address the corporate structure and ownership of electronic markets. In this paper we contrast the consortium-based approach to private (single company) and third party exchanges.

The research is motivated by the current conflicting ideas and uncertainty about the best governance structure for electronic markets. For instance, while General Motors, Ford, and DaimlerChrysler take a joint consortium approach, Volkswagen as well as BMW have started to build private exchange platforms. Taking the automotive industry as an example, our aim is to explore the underlying forces driving these different governance structures. 
Our paper starts with a brief introduction to vertical buy-side electronic markets and develops a framework for the governance structure of electronic markets. In the next part we concentrate on exchange platforms in the automotive industry and describe General Motors's approach with Covisint and Volkswagen's private solution. Building on multiple theories from inter-organizational relationship formation we analyze the advantages and disadvantages of the different exchange structures and illustrate them with our case. In our conclusion we summarize the insights gained from the frameworks and discuss their limitations.

\section{Electronic Markets}

\section{Vertical Buy-side Electronic Markets}

We define an electronic market as an inter-organizational information system that fosters market based exchanges between agents in all transaction phases [Bako97]. A horizontal market addresses a specific function (e.g. human resources, office supplies) and serves a wide range of industries while a vertical market focuses on a wide range of functionalities in a specific industry such as chemicals, steel or automotive. A buy-side electronic market is focused on procurement, supply chain management, and development, while a sell-side market is focused on the demand chain, i.e. the processes by which the goods reach the customer [ArGe00]. This paper concentrates on vertical buy-side electronic markets.

While early electronic markets focused on the transaction itself, more and more additional services are added to these basic functions. Based on the major value chain processes on the buy-side we separate the functionality of electronic markets into three areas:

- E-Procurement refers to all processes concerned with the purchasing of goods and services over the Internet. Thus, e-procurement takes a commerce or transaction perspective. Economies of scale providing liquidity in an electronic market are one of the major success factors.

- Supply Chain Management integrates all activities associated with the flow and transformation of goods from the raw materials stage to the end user. It highlights the coordination perspective between all members of the value chain.

- E-Development provides software tools to facilitate collaborative product design of complex components and modules. It highlights the collaboration between a company and its suppliers in innovation processes. Speed and protection of knowledge assets are key issues. 
The complexity to support these processes by sophisticated tools increases from eprocurement to e-development. Furthermore the processes are not completely independent as for example engineering and procurement will need to work together toward the best overall combination of low prices and customer demand.

\section{Ownership Structures of Electronic Markets}

For a classification of the ownership structure of an electronic market we consider two dimensions to be of particular importance:

- The role of the owners: The owner of the market can be an active market participant (i.e. buyer or seller) or an independent third party acting as an intermediary. This dimension is an external perspective and has significant impact on the goals and therefore the strategy of the owners towards the other parties in the market.

- The competitive relation of the owners: The companies owning and operating the market can be direct competitors outside of this venture or work in different fields and are therefore not competing. This dimension takes an internal perspective and influences the behavior of the market owners towards each other.

This taxonomy results in four different types of ownership structures for electronic markets:

- Private exchanges are owned and operated by a single company or a group of non-competing companies. These companies are also active buyers or sellers in the market.

- A third-party exchange is owned by a group of non-competing companies or a single company that is not considered to be a trading partner, often a start-up company.

- In consortia-led exchanges the ownership is shared between companies that compete outside of this electronic market. They are also active participants in the market.

- We define a meta market as a group of independent market providers who collaborate and exchange requests and offers by interconnecting their market places to increase liquidity.

Figure 1 shows the different approaches and gives examples following the respective governance structure in italics. 


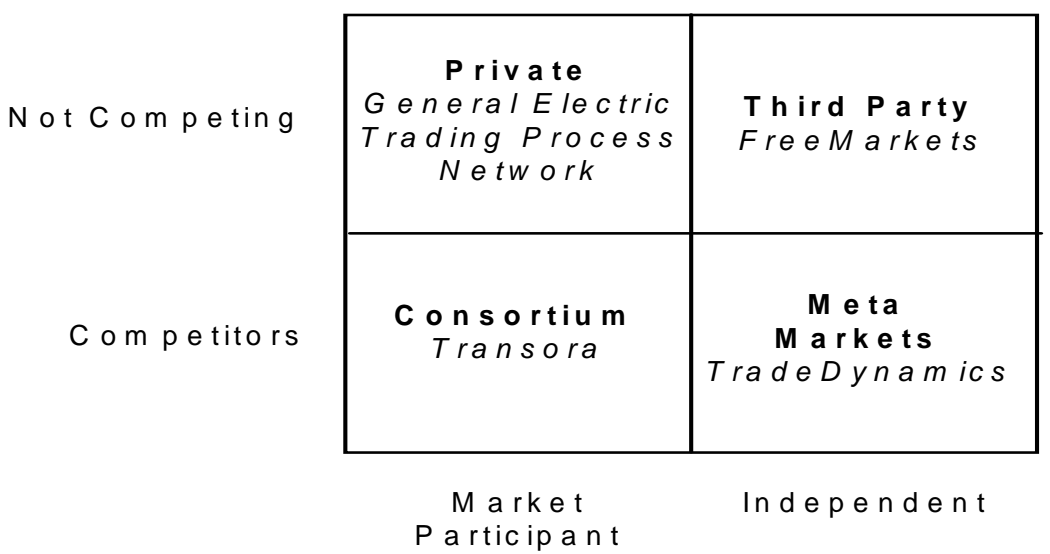

Figure 1: Taxonomy of electronic market ownership structures

Because meta markets are still under development and not in broad use we focus on the remaining three market forms.

\section{Electronic Markets in the Automotive Industry}

The automotive industry is one of the largest and most complex in the world and many activities concerning electronic markets can be observed. In [BaBo01] we provide an overview on electronic market initiatives in the automotive industry. Private exchanges (e.g. Volkswagen, BMW) as well as consortium-based exchanges (e.g. Covisint, SupplyOn) and third party exchanges (e.g. ChoiceParts) have been established.

\section{Covisint}

General Motors (GM) started to use the Internet for procurement activities in 1998 by running some purchases through the independent horizontal exchange FreeMarkets. In November 1999 GM announced the creation of its own private procurement platform called GM TradeXchange. At the same time Ford announced the formation of Auto-Xchange as a central private electronic market for its procurement activities. Both companies started negotiations to consolidate their individual exchange initiatives into one industry-wide trading exchange. In February 2000 they announced that rather than pursue separate, private exchange initiatives they would join forces to create the consortium-based market Covisint and include DaimlerChrysler as a third manufacturer. In April 2000 Nissan and Renault stated their intention to join the partnership. 
The aggregated purchasing volume of the three founders of Covisint is about US\$ 240 billion. The Covisint concept is planned to be the central exchange not only for the participating manufacturers but also for all other members of the supply chain. If all suppliers use the exchange for their own purchasing a volume of US\$ 500 to US\$ 800 billion is calculated.

Covisint intends to cover all three functional areas of vertical buy-side electronic markets identified above, i.e. e-procurement, supply chain management, and e-development. Most applications are presently in the design phase. Covisint stresses that its applications will not replace existing solutions - such as ERP systems - in the participating companies but merely provide a common interface.

The purchasing volume of the Volkswagen Group (VW) is about US\$ 42 billion. To better integrate their suppliers Volkswagen built private internet-based solutions. The Volkswagen SupplyNet (www.vw-zulieferer.de) and the Electronic Supplier Link (esl.Volkswagen.de) are two examples. The Electronic Supplier Link currently connects about 3,000 suppliers and offers a simple internet-based data exchange.

Volkswagen did not join Covisint but announced a strategic partnership with IBM, i2, and Ariba to build a private online exchange platform in April 2000. The main reasons cited were that Volkswagen focuses on the efficiency of its supply chain instead of price reduction [Menz00]. Furthermore it raised some doubts on information security as well as regulatory issues [Reink00]. Volkswagen's exchange will not be run as a separate company but within the existing structures.

\section{Alone or Together? - A Multi-perspective Analysis}

Several theoretical frameworks have been used to explain the formation of interorganizational relationships (see e.g. [GrSo95, BaHa00]). KUMAR et al. show in their analysis of the adoption of inter-organizational information systems, that the use of a single theoretical perspective to explain observed phenomena falls short of capturing the complexity involved in the formation of relationships [Kumar98]. There is often a portfolio of reasons for alliance formation or for staying away from an alliance. In particular, following KUMAR et al., we argue that only a combination of technical-economic as well as socio-political perspectives can help to understand complex inter-organizational systems.

Electronic market research has concentrated on the economic aspect in comparison to organizational alternatives (e.g. hierarchies, see [Bako98]) so far. As we will show, this perspective falls short of explaining the different approaches to electronic markets. In the following sections we investigate and combine six major theoretical paradigms as identified by [BaHa00] that span from economic to behavioral: Transaction cost economics, resource dependence, stakeholder theory, an 
organizational learning perspective, institutional theory, and a strategic choice position are used. We apply these theories to the ownership structure of electronic markets in general and illustrate the viewpoints with details from the automotive industry using the cases of General Motors and Volkswagen.

\section{Transaction Cost Economics}

Transaction cost economics [Will75] offers an economic perspective on organizational relations. It contrasts organizational alternatives by comparing their respective sum of transaction costs (i.e. internal and external coordination costs) and production costs. The existence of inter-organizational relationships such as consortia expands the "classical" make or buy decision to make, buy or partner. For our investigation we break down the total cost to set-up costs, product costs, coordination costs and switching costs [NgBr99, p. 354].

Set-up Costs: As a consortium-based electronic market sets a standard for communication and coordination between participants that gets wide acceptance in the industry due to the support of leading companies it can be expected that the set-up costs will be lower than in a private electronic market. Third-party start-ups and private markets may have to convince initial members to join when benefits are lower. The more partners are on the other hand involved in a consortium the more complex it will be to adopt to their existing back-end IT systems. Additional interfaces will have to be specified and the harmonization of processes can be expected to be a long and tedious procedure.

In the automotive industry first tier suppliers are more or less forced to work with all manufacturers and traditionally have adapted to their technological requirements. Thus each of the big manufacturers will be able to impose its standards on the suppliers and set-up costs will not make a big difference from their perspective. But for Covisint it will be difficult e.g. to integrate all the different CAD systems in use as well as the back-end ERP systems. Volkswagen can tailor and optimize its market to its own systems.

Production Costs: A consideration of production costs shows that the process costs in a private solution will probably be lower due to an easier and better technical integration into the internal IT systems of the buyer. Another production cost related question is the price of the acquired products and services. A consortiumbased e-marketplace can start with liquidity introduced by its owners. The buying power of the consortium-partners can help to receive volume rebates in procurement.

It has been shown that the expected relative savings in the automotive value chain in the US and in Europe are very similar [BaBo01] and thus do not explain the different approaches of Volkswagen and GM. Due to regulatory issues consortia of automotive manufacturers will not be allowed to pool their demand for direct pro- 
duction parts. This will only be possible for indirect maintenance, repair, and operations (MRO) materials. It can however be expected that Volkswagen will be able to achieve similar savings either through other horizontal markets or by inviting participants from outside the industry to join.

Coordination Costs: In an industry with fragmented sellers and buyers a consortium is not very likely due to the increased coordination efforts. It can be expected that third parties will aggregate demand and supply on their platforms. Consortiums are likely to emerge only if a limited number of buyers or sellers with significant market power exist. But private marketplaces can also materialize given that the owner has a strong market position. In a situation with a highly concentrated buy and sell side the efforts of building a marketplace will probably not pay off and direct relations will be established.

The automotive industry is characterized by a small number of large automotive manufacturers each having a massive buying power. Thus a consortium as well as a private approach to electronic markets seems possible from this perspective.

Switching Costs: If the consortium welcomes additional members it can be considered to be less expensive to change from a private exchange to a consortium than vice versa. The new member can buy into the established platform and start using the established services immediately. It can be assumed to be harder for consortium-members to abandon the membership and to build an in-house solution from scratch.

With its proprietary solution Volkswagen retains the option to switch. If their marketplace model fails, it might be easier for Volkswagen to stop the project than for competitors that own stakes in Covisint. If one of the exchanges succeeds, Volkswagen will either expand its own platform or join Covisint. Given Covisint's open standards and its commitment to attract the largest number of participants possible, switching is not likely to put Volkswagen in a serious competitive disadvantage.

Summarizing, the transaction cost perspective does not clearly favor a specific ownership structure. Although our case analysis did not show any significant differences in the environment as well as in the motivations of GM and VW they nevertheless chose different alternatives. For that reason an investigation of additional theoretical perspectives is needed.

\section{Resource Dependence Theory}

The resource dependence view [PfSa78] argues that firms partner to get access to critical resources and thereby decrease dependence on other organizations. From another perspective companies could also engage in partnerships to increase the dependence of other organizations on them. 
The pooling of resources can be a reason to form an alliance for an electronic market. Primarily partnerships with technology providers can be explained with this argument. They assure access to up-to-date technology and have a positive influence on future product developments. The pooling of complementary skills can help to build the market faster and to capture first-mover advantages. The resource dependence framework can also explain the partnering with otherwise competing market participants if the combined efforts can produce a product or service that is unique and only imperfectly imitable [Barn91]. The partners could set up a market with huge buying power and exclusive services to its members and exclude others from the cooperation.

It can be safely assumed, that in the automotive industry the knowledge of building and running an electronic market platform is relatively limited for all the manufacturers. They can try to pool their domain expertise but even here the knowledge within the different companies is very similar. The dependency between the different levels of the supply chain is traditionally very high in the automotive industry. Following a consortium-based approach introduces a new dependency between the participating manufacturers.

Covisint explicitly invites all industry participants to join the initiative. Its goal therefore is not to produce a non-imitable and rare service but to foster an industry-wide standard for cooperation. While the addition of Renault and Nissan to Covisint can be explained to gain better access to the local European and Asian markets, the cooperation between GM, Ford and DaimlerChrysler can not be explained using this framework.

For Volkswagen the risk of becoming dependent on Covisint partners paired with the partial loss of decision autonomy outweighs possible advantages. This perspective is closely linked to the question of a trustworthy relationship required for a close cooperation. Typically, mutual trust is established slowly, originating in minor interactions requiring little risk then progressing to major commitments [JiRo99]. Nevertheless VW signaled the willingness to cooperate on standardization issues.

Covisint can also be seen as a vehicle for collective lobbying [Oliv90] to increase power and pressure on suppliers to adopt policies favorable to the founders. By aggregating more than $50 \%$ of the buying power in the industry the Covisint exchange is just too big to be ignored by suppliers. Also suppliers sign up more quickly because there is not too much confusion as to which exchange might win. While Volkswagen supports the idea of an industry-wide standard [Reut00] it faces the danger of being left behind in the development of an industry-wide platform.

Finally Covisint's founders may have formed the alliance simply because each of them perceived it did not have the necessary resources to gain control of new Internet B2B channels before anyone else does. In the case of GM the formation 
of Covisint can be seen as a pre-emptive strike against start-up companies, especially its former partner FreeMarkets.

As a result the resource dependence view suggests that companies have to weigh the benefits of pooling complementary expertise against the possible dangers of becoming dependent on competitors who are partners in a consortium. This is also true for a possible dependence on a third party player.

\section{Stakeholder Theory}

The stakeholder theory [Free94] states that organizations form to align their own interests with the interests of their stakeholders such as suppliers, shareholders, employees, and customers.

The main stakeholders of an electronic market - besides shareholders and employees - are the buyers, sellers, and the technology providers. Since a market can only work with buyers and sellers present, the fair consideration of both interest groups is essential. From a third-party exchange perspective this is an argument to invite sellers and buyers to take a stake in the company. If the owner of the marketplace is also a market participant (buyer or seller) the complementing stakeholders could be invited to join to align interests. In many market places technology providers are bound financially to the success of the exchange in order to increase their commitment.

In the case of the automotive exchanges this would mean to invite sellers, i.e. suppliers to join the alliance. The founding manufacturers own Covisint and only a small minority stake was given to the two major technology providers. It is not planned to extend this to suppliers. Nonetheless it is officially stated that one of the reasons to form Covisint was the request of suppliers to reduce the number of interfaces in the industry. Nevertheless many suppliers are skeptical of win-win promises by the alliance of carmakers. They fear that the exchanges will cut into profit margins or turn their products into commodities. As a reaction several European suppliers have founded their own marketplace (SupplyOn, www.supplyon.com) and a group of leading American suppliers is also considering starting their own venture [Litt00].

The addition of other manufacturers to the consortium can only be explained by taking a holistic view at the industry and focusing on Covisint's stated goal to transform the whole automotive industry. The Volkswagen initiative is completely integrated into its other operations. The technology partners receive no equity stake and no other revenue sharing mechanisms are implemented. Not joining Covisint and highlighting the supply chain integration issues may also be explained by Volkswagen's still damaged image with the suppliers that originates from the "Lopez-era" that was characterized by high price pressure and is seen as 
a mistake within VW today [Henk00]. Volkswagen still has to rebuild trust with its suppliers and a participation in Covisint can be seen as contra productive.

Focusing on shareholder value General Motors realized that the value it brought to the independent company FreeMarkets by increasing its stock value outweighed the value FreeMarkets brought to GM. According to analysts' opinions an initial public offering of Covisint could eventually have a market capitalization of US $\$ 30$ billion to US\$ 40 billion [Menz00].

Summarizing the stakeholder perspective, a consortium that is floated as an independent company can be in the interest of shareholder value. This potential benefit has to be weighed against the possible negative reactions of excluded stakeholders as for example suppliers. In our case study Volkswagen seems to put more weight on supplier cooperation and less on the potential financial valuation of a powerful consortium while GM puts shareholder value in the center of its decision.

\section{Organizational Learning}

Organizational learning [Dodg93] is concerned with all processes that lead to new knowledge in the organization, assimilate it, and apply it to a business setting. With respect to inter-organizational relationships a company can absorb knowledge from partners and increase its organizational competencies.

This theory can be used as an explanation for the collaboration between start-up, technology, and consulting companies with established old-economy firms to establish electronic markets.

Covisint is part of GM's e-GM initiative. This initiative has a clear mission to bundle e-business activities within GM and also to apply its results to the rest of the company. But this does not explain why Covisint had to be founded as a consortium with other manufacturers. It can be safely assumed that the knowledge about e-markets within the big car manufacturers is fairly equally distributed. So a knowledge transfer cannot be expected from the collaboration. To the contrary the newly created knowledge resides primarily in the new organization and it may be difficult to get it back into the own company, as the knowledge is then either bound to teams that cooperate with a number of major OEMs (implicit knowledge) or owned by outsourcing-partners.

By developing its own exchange, Volkswagen guarantees that the acquired knowledge stays within the company. Another perspective is that VW acquires a learning option: Because the automaker's own staff accumulates knowledge in managing electronic trading platforms, Volkswagen maintains flexibility. If similar platforms are considered suitable e.g. for internal logistics at a later stage, Volkswagen will be able to initiate projects on the basis of past experiences with the technology. 
While learning theories concentrate on skill development the danger of losing confidential information should also not be neglected. This is especially true for information on products, prices, inventory and orders, as well as for e-development. Covisint expects that a sophisticated security system will solve this issue.

Taking the organizational learning perspective the learning opportunities in a joint venture have to be weighed against the possible lock-in of intellectual capital in the consortium and the danger of losing confidential information. While VW stresses potential dangers GM seems to concentrate on opportunities and is relying on technological solutions.

\section{Institutional Theory}

The basic assumption of institutional theory [DiPo83] is that firms organize to appear legitimate and conform to prevailing social norms even if there are no technical of economical advantages.

In the electronic market domain this could mean that several companies form an electronic market or a company joins an existing market because "everybody has to do this Internet thing" and the visibility of the company is increased through participation. Another aspect is that often system integrators and investment banks bring together the participants of a consortium. In a later stage they are billing for consulting and financial arrangements and have an interest that these ventures carry on until an initial public offering (IPO).

Some of the early statements about the buying power collected in Covisint and the possible valuation after an IPO point in this direction. At the time of Covisint's announcement the B2B wave was on its heights and many old economy companies tried to be perceived as part of the new Internet economy. Volkswagen takes a more conservative approach as it sees the new technology primarily as strategic enabler and not as financial investment.

Summarizing, the institutional theory suggests that the move to join a consortium may be shortsighted unless backed by more substantial arguments than current movements. The different perspectives of VW and GM mirror a more conservative approach to financial markets vs. a clear focus on capital markets.

\section{Strategic Choice}

The strategic choice argument states that firms pursue alliances to increase competitiveness and market power [Barn91]. In general this means that, in the case of a consortium, all members should profit, at least in comparison to non-consortium members. 
So while Volkswagen can gain a competitive advantage over others by implementing its own systems, the members of Covisint will have to concentrate their efforts on non-Covisint activities. This refers to the general question whether information technology by itself can help firms to gain competitive advantage or whether it is considered to be an imitable and substitutable resource and only IT management skills are considered a source of competitive advantage [MaFu95].

\section{Conclusion}

The theories we used to investigate the question of organizational structures for electronic markets fall along a conceptual continuum from economic (transaction cost economy) to behavioral (institutional theory) and also include strategic considerations. As shown in our analysis none of the theories clearly suggests one or the other organizational structure, but each of them contributes to our overall understanding of the partnering processes for electronic markets.

The analysis presented throughout this paper can be summarized along three main dimensions:

- Cost Perspective: Transaction costs provide a economic perspective looking at set-up costs, production costs, coordination costs, and switching costs. Complex and specific products and processes require shifting the focus from product price to coordination aspects like supply chain management and e-development. These suggest an individual private market instead of a consortium approach.

- Capabilities Perspective: In contrast to the transaction cost approach, which emphasizes cost minimization, the resource dependence rationale emphasizes value maximization through the use of internal and external resources. This view is closely related to the organizational learning perspective, which recognizes that resources can also be build up internally over time. The company has to weigh its own capabilities against externally available ones. Strong internal competencies relative to the market suggest a private exchange while weak capabilities suggest using an independent third party. The consortium can be used if the technology is generally not well understood.

- Competitive Advantage Perspective: The remaining three theories (institutional theory, stakeholder theory, strategic choice) relate to the competitive advantage of a company. Based on the strategic choice theory in the early stages of e-markets the highest competitive advantage can be achieved by building a private market and the lowest by joining a consortium. This may be different if e-markets become a commodity in the future. The stakeholder theory gives the option to directly focus on shareholders and financial markets with a consortium IPO or to focus on business partners and long-term success with a private 
solution. The institutional theory puts organizational behavior in the cultural context and is useful to reflect on decisions as well as to explain organizational behavior.

It has to be stressed that participating in a consortium-based exchange or using a proprietary market is not an either-or decision. VW as well as Covisint claim to be open to possible future collaborations. In fact suppliers in the automotive industry plan to join Covisint for their sell-side and forge other activities for their own buyside. In general the Covisint example shows that consortium-based exchanges will face problems unless both buyer and seller see value in joining the exchange. Buyer-managed exchanges will have to offer an open dialogue (and equity) to the suppliers in order to align interests.

Concluding this implies that the advantages and disadvantages to participate in a consortium must be carefully weighed, taking multiple perspectives into account. In this paper we have developed a taxonomy of governance models for electronic markets, applied it to the automotive industry and finally structured the reasons for consortium-based and proprietary exchanges. This is the first step to a more comprehensive contingency framework.

Supplementary research is needed to extend these results to sell-side markets and markets in other industries. Another question to be examined is whether electronic markets exhibit a life cycle, e.g. from third-party through consortium-based to proprietary, or whether different market governance structures will exist in parallel.

\section{References}

[ArGe00] Archer, N. and Gebauer, J. (2000) Managing In The Context of The New Electronic Marketplace. Proceedings 1st World Congress on the Management of Electronic Commerce, Hamilton, Ontario, Canada, January 19-21, 2000.

[Bako97] Bakos, Y. (1997) Reducing Buyer Search Costs: Implications for Electronic Markets. Management Science, Vol. 43 (12), 1676-1692.

[Bako98] Bakos, Y. (1998) The Emerging Role of Electronic Marketplaces on the Internet. Communications of the ACM, Vol. 41 (8), 35-42.

[BaBo01] Baldi, S. and Borgman, H. P. (2001) Consortium-based B2B E-Marketplaces - A Case Study in the Automotive Industry. Proceedings 14th Bled Electronic Commerce Conference, Bled.

[Barn91] Barney, J. (1991) Firm Resources and Sustained Competitive Advantage. Journal of Management, Vol. 17 (1), 99-120. 
[BaHa00] Barringer, B. R. and Harrison, J. S. (2000) Walking the Tightrope: Creating Value Through Interorganizational Relationships. Journal of Management, Vol. 26 (3), 367-403.

[DiPo83] DiMaggio, P. and Powell, W. (1983) The Iron Cage Revisited: Institutional Isomorphism and Collective Rationality in Organizational Fields. American Sociological Review, Vol. 48, 147-160.

[Dodg 93] Dodgson, M. (1993) Organizational Learning: A Review of Some Literature. Organization Studies, Vol. 14, 375-394.

[Free94] Freeman, R. E. (1994) Ethical Theory and Business. Prentice-Hall, Englewood Cliffs, New Jersey.

[GrSo95] Grandoni, A. and Soda, G. (1995) Inter-firm Networks: Antecedents, Mechanisms and Forms. Organizational Studies, Vol. 16 (2), 183-214.

[GrRa99] Grover, V. and Ramanlal, P. (1999) Six Myths of Information and Markets: Information Technology Networks, Electronic Commerce, and the Battle for Consumer Surplus. MIS Quarterly, Vol. 23 (4), 465-495.

[Henk00] Henke, J. W. (2000) Pipe Dream or Reality? Ward's Auto World, Vol. 36 (2), 21.

[JiRo99] Jin, L. and Robey, D. (1999) Explaining Cybermediation: An Organizational Analysis of Electronic Retailing. International Journal of Electronic Commerce, Vol. 3 (4), 47-65.

[Kumar98] Kumar, K., Dissel, H. G. v. and Bielli, P. (1998) The Merchant of Prato - Revisited: Toward a Third Rationality of Information Systems. MIS Quarterly, Vol. 22 (2), 199-226.

[Litt00] Little, D. (2000) Let's Keep this Exchange to Ourselves. Business Week (3710), 48.

[MaFu95] Mata, F. J. and Fuerst, W. L. (1995) Information technology and sustained competitive advantage: A resource-based analysis. MIS Quarterly, Vol. 19 (4), 487-506.

[Menz00] Menzel, S. (2000) Volkswagen Forgoes Alliance To Develop New Internet Plan. The Wallstreet Journal Interactive Edition, April 13, 2000.

[NgBr99] Ngwenyama, D. K. and Bryson, N. (1999) Making the Information Systems Outsourcing Decision: A Transaction Cost Approach to Analyzing Outsourcing Problems. European Journal of Operational Research (115), 351-367.

[Oliv90] Oliver, C. (1990) Determinants of Interorganizational Relationships: Integration and Future Directions. Academy of Management Review, Vol. 15, 241-265.

[PfSa78] Pfeffer, J. and Salancik, G. R. (1978) The External Control of Organizations: A Resource Dependence Perspective. Harper and Row, New York.

[Rein00] Reinking, G. (2000) Volkswagen: Lufthansa soll auf VWs Internet-Marktplatz landen. Financial Times Deutschland, 24. Mai 2000, Online: http://www.ftd.de/ub/in/ FTDOVI28N8C.html, (accessed: January 18, 2001). 
[Reut00] Reuters (2000) VW: Autokonzern hält sich Teilnahme an Internet-Marktplatz offen. Financial Times Deutschland, 29. Februar 2000, Online: http://www.ftd.de/ub/in/ FTDCHF4U95C.html, (accessed: January 18, 2001).

[WaCh00] Walravens, P. D. and Chung, S. C. (2000) Today Many B2B Enablers, Tomorrow a Few Commerce Networks. Lehman Brothers, June 20, 2000.

[Will75] Williamson, O. E. (1975) Markets and Hierarchies: Analysis and Antitrust Implications. The Free Press, New York. 